\title{
Virological and Immunological Long-Term Outcome of Human Immunodeficiency Virus-1 Infected Children Treated before One Year and after Two Years of Age in a Resource-Limited Setting of South Africa
}

\author{
Jean-Christophe Beghin ${ }^{1,2 *}$, Jean Ruelle ${ }^{1,3}$, Patrick Goubau ${ }^{1,3}$, Malini Krishna ${ }^{4}$, Leslie Hall ${ }^{5}$ and Dimitri Van der Linden ${ }^{6}$ \\ ${ }^{1}$ AIDS Reference Laboratory, Université catholique de Louvain, Brussels, Belgium \\ ${ }^{2}$ Department of Pediatric Pulmonology, Hôpital Universitaire Des Enfants Reine Fabiola, Brussels, Belgium \\ ${ }^{3}$ Department of Microbiology, Cliniques Universitaires Saint Luc, Brussels, Belgium \\ ${ }^{4}$ HIV Clinic, Edendale Hospital, Edendale, South Africa \\ ${ }^{5}$ General Pediatrics, Edendale Hospital, Edendale, South Africa \\ ${ }^{6}$ Department of Paediatric Infectious Diseases and General Paediatrics, Cliniques Universitaires Saint-Luc, Université catholique de Louvain, Brussels, Belgium
}

\begin{abstract}
Introduction: Benefits of early Highly Active AntiRetroviral Therapy (HAART) to reduce infant mortality and morbidity have been demonstrated in resource-limited and rich settings. However, immunovirological data collected in Sub-Saharan Africa are scarce. This study describes the long-term outcome of South African children who started HAART before one year of age (Early Starters Cohort or ESC) and compare their immunovirological outcomes to children who started their therapy after two years of age (Late Starters Cohort or LSC). Immunovirological results will be compared in order to evaluate the long-term non-inferiority of early treatment initiation.
\end{abstract}

Methods: Fifty-five children were included in the ESC (mean follow-up period 7.9 years) and 96 children were included in the LSC (mean follow-up period 6.3 years). Children from the ESC and the LSC were subdivided into three subgroups according to CD4\% at HAART initiation ( $<15 \%$, between $15-24 \%$ and $\geq 25 \%$ ).

Results: All children included in the ESC achieved normal CD4 $\%$ at least once during the entire follow-up period, contrary to the LSC where $89.6 \%$ children achieved normal CD4 $\%(p=0.014)$. Furthermore, mean CD4 $\%$ became higher in the ESC six years after treatment initiation. Children with $\mathrm{CD} 4 \%$ between 15 and $24 \%$ at HAART initiation reached higher $\mathrm{CD} 4 \%$ in the ESC, three years after treatment initiation. The proportion of children who experienced virological failure $(>1000 \mathrm{cp} / \mathrm{ml})$ was comparable in both cohorts but persistent undetectable viral load $(<50 \mathrm{cp} / \mathrm{ml})$ after initial virological suppression was more frequent in the ESC $(p=0.008)$. Finally, the proportion of children with detectable viral loads ( 50 to $1000 \mathrm{cp} / \mathrm{ml})$ at least once after initial virological suppression was higher in the LSC $(p=0.0022)$.

Conclusion: HAART appeared highly effective in terms of immunovirological outcomes both in children treated before one and after two years of age. The results of this study demonstrate that early treated children more often achieved normal $\mathrm{CD} 4 \%$, tended to have higher mean $\mathrm{CD} 4 \%$ and more sustained virological suppression. These results encourage the current international recommendations to initiate HAART as soon as possible in RLS.

Keywords: HIV; Children; Resource-limited setting; Long-term; South Africa; Treatment

\section{Introduction}

In 2010 the World Health Organization (WHO) recommended an immediate start of Highly Active AntiRetroviral Therapy (HAART) in all patients diagnosed with HIV before 2 years of age [1]. This recommendation was extended to children younger than 5 years of age in 2013 [2] and to all children and adults in 2015 [3]. Benefits of early treatment initiation on infant mortality [4,5], neurodevelopmental outcome [5,6], growth recovery [7], immunologic restoration and virological suppression $[8,9]$, have been demonstrated in short term follow-up studies implemented in resource-limited settings (RLS). A systematic review including 5 African studies, showed a 12 months HIV RNA suppression rate of $70 \%$ and a $\mathrm{CD} 4^{+}$cell percentage $\left(\mathrm{CD} 4^{+} \%\right)$ increase of $13.7 \%$, for children initiating HAART in RLS [10].

Between 2005 and 2014, children treated with HAART increased from 71.500 to 824.000 [11] but long-term ( $>3$ years) virological and immunological data collected in Sub-Saharan Africa are scarce [12-16]. Children are at risk to develop treatment failure due to inappropriate antiretroviral formulations, adherence difficulties, drug toxicity or development of resistance [17].

The aim of this study is to describe the long-term outcome in a real life setting of children who started HAART before 1 year of age (early starters cohort or ESC) and after 2 years of age (late starters cohort or LSC) in the same RLS of KwaZulu-Natal, South Africa (SA). Immunovirological results will be compared in order to know if early treatment initiation, which is a major advantage in a short-term point of view, could lead to a poorer long-term evolution in terms of $\mathrm{CD} 4 \%$ and viral load (VL).

\section{Method}

\section{Study population and setting}

This non-inferiority retrospective study was conducted in SA

*Corresponding author: Jean-Christophe Beghin, AIDS Reference Laboratory Université Catholique de Louvain Av. Hippocrate 54, bte B1.54.05, 1200 Bruxelles, Belgium, Tel: +3227645492; Fax: +3227649440; E-mail: medjis@hotmail.com

Received April 20, 2017; Accepted April 27, 2017; Published May 04, 2017

Citation: Beghin JC, Ruelle J, Goubau P, Krishna M, Hall L, et al. (2017) Virologica and Immunological Long-Term Outcome of Human Immunodeficiency Virus-1 Infected Children Treated before One Year and after Two Years of Age in a Resource-Limited Setting of South Africa. J AIDS Clin Res 8: 690. doi: 10.4172/2155-6113.1000690

Copyright: ( 92017 Beghin JC, et al. This is an open-access article distributed under the terms of the Creative Commons Attribution License, which permits unrestricted use, distribution, and reproduction in any medium, provided the original author and source are credited. 
Citation: Beghin JC, Ruelle J, Goubau P, Krishna M, Hall L, et al. (2017) Virological and Immunological Long-Term Outcome of Human Immunodeficiency Virus-1 Infected Children Treated before One Year and after Two Years of Age in a Resource-Limited Setting of South Africa. J AIDS Clin Res 8: 690. doi: 10.4172/2155-6113.1000690

Page 2 of 7

between September and December 2014 at Edendale Regional Hospital located in a peri-urban and RLS of KwaZulu-Natal. The overall prevalence of HIV is the highest of SA with $16.9 \%$ of people infected [18].

In total, hundred fifty-one children were included in the present study in the ESC and the LSC.

Children in the ESC were included in a previous study about feasibility and effectiveness of early HAART initiation in RLS, which took place between 2005 and 2008 [19]. First condition to be included in this previous study was to be younger than 1 year of age at HAART initiation (median 8.6 months, range 2.1-11.9 months). Other criteria to initiate HAART included positive HIV-1 DNA PCR, WHO stage 2-4 and/or $\mathrm{CD} 4 \%<30 \%$ [19].

Children included in the LSC were invited to participate to the present study during a planned appointment in the HIV clinic. Inclusion criteria were to have initiated HAART after 2 years of age in the HIV clinic and to be vertically infected according to HIV status of the mothers. Age at HAART initiation had to be mentioned in the patient's file. These children were not included in the previous study between 2005 and 2008 because they were older than 1 year during this period or because they started HAART after 2008. They initiated HAART in function of their WHO clinical stage, $\mathrm{CD} 4^{+} \%$ or comorbidities following the successive South African guidelines between 2005 and 2012.

Children from both cohorts came from the same region with the same socio-economical environment. They were followed-up by the local staff between 2008 and 2014 and were treated following the national recommendations.

\section{Study procedures}

Parents or caregivers gave a written informed consent prior any procedure. Data were collected from the medical files (before 2010 records on paper and later on computer). The study was approved by the South African ethical committee «Umgungundlovu Health District Review Board (UHERB)» and the Belgian Ethical committee «Comité d'Ethique Hospitalo-Facultaire Saint Luc - UCL».

\section{Definitions}

Children with $\mathrm{CD}^{+} \%<15 \%$, between $15-24 \%$ and $\geq 25 \%$ at treatment initiation were described as low (LIS), intermediate (IIS) and high (HIS) immunological subgroups.

Virological failure was defined as a VL above 1000 copies $/ \mathrm{mL}$ based on the annual blood check. $\mathrm{mL}$.

Viral suppression was obtained when VL was less than 50 copies/

\section{Laboratory procedures}

Blood samples were analyzed during routine consultation at the Edendale Hospital laboratory. $\mathrm{CD}^{+}$count was analyzed by flow cytometer FC 500 series $^{\circ}$ from Beckman Coulter (Paris France) and expressed as \% of leucocytes and absolute value. VL was measured by real time PCR with the "COBAS" AmpliPrep/COBAS ${ }^{\circ}$ TaqMan ${ }^{\circ} \mathrm{HIV}$ 1 Test, v2.0 (Roche Diagnostics)". The lower limit of quantification (LLOQ) was 20 copies $/ \mathrm{mL}$.

\section{Current South African antiretroviral treatment guidelines}

All infants and children under 3 years of age ( $0 \mathrm{r}<10 \mathrm{~kg}$ ) are treated with Abacavir (ABC), Lamivudine (3TC) and Lopinavir boosted ritonavir $(\mathrm{LPV} / \mathrm{r})$ when they initiate their treatment. Children over 3 years of age are treated with ABC, 3TC and Efavirenz (EFV) [20]. Before 2010, guidelines recommended to start treatment with Stavudine ( $\mathrm{d} 4 \mathrm{~T})$ instead of $\mathrm{ABC}$ [21].

\section{Statistical analysis}

Immunological and virological mean values were compared with the Student $t$ test. Proportions between the ESC and the LSC were compared with the exact Fisher test. Differences in CD4 means were also tested with the non-parametric Wilcoxon test, which resulted in p-values similar to the ones obtained with the t-test.

\section{Results}

\section{Study population}

From the 94 subjects described in the 2005-2008 study [19], 55 were included in the present research ( 23 females and 32 males). The remaining 36 patients were transferred to other centers and lost to follow-up (33/36) or died (3/36). Mean age at inclusion was 9.6 years (range 7.1-10.5 years) with a mean follow-up period of 7.9 years (range 6.8-9.8 years).

The control group (LSC) included 96 subjects (42 females and 54 males) who initiated HAART after 2 years of age (median 4.3 years range 2.0-7.6 years) between 2005 and 2012. Mean age was 10.6 years (range 6.6-14.8 years) and the mean follow-up period was 6.3 years (range 2.5-9.8 years).

\section{Initial therapies}

In the ESC, $98 \%$ of children were initiated on HAART with a regimen including one protease inhibitor (PI) and two nucleoside reverse transcriptase inhibitors (NRTIs) and 2\% with one nonnucleoside reverse transcriptase inhibitor (NNRTI) and two NRTIs.

In the LSC, $12 \%$ of children were initiated on HAART with a regimen including one PI and two NRTIs (children between two and three years of age at treatment initiation) and $88 \%$ with one NNRTI and two NRTIs (children older than three years at treatment initiation) (Table 1). Only 5 children were followed-up after 8 years in each cohort; therefore the results are not shown for any longer period of time.

\begin{tabular}{|c|c|c|c|}
\hline PI/NNRTIs & NRTIs & ESC & LSC \\
\hline Lopinavir/ritonavir & Stavudine/Lamivudine & $50 / 55(91 \%)$ & $12 / 96(12 \%)$ \\
\hline Lopinavir/ritonavir & Zidovudine/Lamivudine & $4 / 55(7 \%)$ & $/$ \\
\hline Nevirapine & Stavudine/Lamivudine & $1 / 55(2 \%)$ & $/$ \\
\hline Efavirenz & Stavudine/Lamivudine & $/$ & $55 / 96(58 \%)$ \\
\hline Efavirenz & Abacavir/Lamivudine & $/$ & $28 / 96(29 \%)$ \\
\hline Efavirenz & Zidovudine/Lamivudine & $/$ & $1 / 96(1 \%)$ \\
\hline
\end{tabular}

PI: Protease Inhibitor; NNRTI: Non-Nucleoside Reverse Transcriptase Inhibitors; NRTI: Nucleoside Reverse Transcriptase Inhibitor; ESC: Early Starters Cohort; LSC: Late Starters Cohort

Table 1: HAART regimen at treatment initiation in early and late starters cohorts.

\section{Switch of therapy}

A large proportion of children have changed treatment in both cohorts mainly due to revisions of the national recommendations. ESC and LSC replaced d4T by another NRTI (ABC, AZT or TDF) in $78 \%$ and $52 \%$ of patients respectively regardless of virological failure.

Switch to a second line of HAART due to virological failure was not significantly different between the ESC (11\%) and the LSC (14\%) ( $p=$ 
Citation: Beghin JC, Ruelle J, Goubau P, Krishna M, Hall L, et al. (2017) Virological and Immunological Long-Term Outcome of Human Immunodeficiency Virus-1 Infected Children Treated before One Year and after Two Years of Age in a Resource-Limited Setting of South Africa. J AIDS Clin Res 8: 690. doi: 10.4172/2155-6113.1000690

Page 3 of 7

0.624). Successive lines of treatment after virological failure are detailed in Table 2.

Among the ESC, one patient replaced AZT for d4T due to anemia and one patient changed from LPV/r to EFV (reason not specified). Among the LSC, one child changed from EFV to LPV/r due to drowsiness (data not shown).

\section{Immunological outcome}

Mean $\mathrm{CD} 4^{+} \%$ at HAART initiation was not significantly different and increased in the same proportions, in the ESC and the LSC during the first five years after treatment initiation $(+18.3 \%$ vs. $+16.2 \%)$. The largest increase occurred during the first year of therapy in cohorts $(+13.8 \%$ vs. $+11.9 \%)$. Six years after treatment initiation, mean $\mathrm{CD} 4 \%$ stayed significantly higher in the ESC (Figure 1 and Table 3 ).

All children included in the ESC (55/55) achieved normal CD $4^{+} \%$ at least once during the entire follow-up period, contrary to the LSC where $86 / 96(89.6 \%)$ children achieved normal CD $4^{+} \%(\mathrm{p}=0.014)$.

In a second analysis, results were subdivided in three subgroups in function of the $\mathrm{CD} 4^{+} \%$ at HAART initiation (as explained in the definitions paragraph). First subgroup is the LIS (47\% of the ESC vs. $56 \%$ of the LSC), second is the IIS ( $37 \%$ of the ESC vs. $32 \%$ of the
LSC) and third is the HIS (16\% of the ESC vs. $12 \%$ of the LSC). The proportion of children included in each subgroup was not significantly different in both cohorts ( $p=0.56,0.47$ and 0.74 , respectively).

LIS from both cohorts had comparable mean $\mathrm{CD} 4 \%$ at HAART initiation and during the entire follow-up period $(p>0.05)$. Mean $\mathrm{CD} 4^{+} \%$ became higher than $25 \%$ in both cohorts after two years of treatment (Figure 2 and Table 4). In the ESC, 26/26 children achieved normal $\mathrm{CD} 4 \%$ at least once during the entire follow-up period and $47 / 54(87 \%)$ children achieved normal CD4 $\%$ in the LSC ( $\mathrm{p}=0.089)$.

IIS from both cohorts had comparable mean $\mathrm{CD} 4^{+} \%$ at HAART initiation but in children from the ESC it became and stayed significantly higher than in the LSC, three years after HAART initiation. Mean CD $4 \%$ became higher than $25 \%$ in both cohorts after two year of treatment (Figure 2 and Table 4). In the ESC, 20/20 children achieved normal $\mathrm{CD} 4+\%$ at least once during the entire follow-up period, and $27 / 30$ (90\%) children achieved normal CD4 ${ }^{+} \%$ in the LSC $(\mathrm{p}=0.27)$.

HIS from both cohorts had comparable mean $\mathrm{CD} 4 \%$ at HAART initiation and during the entire follow-up period $(p>0.05)$ except at six months of treatment ( $27.1 \%$ vs. $42.7 \%$, respectively). Mean CD $4 \%$ stayed higher than $25 \%$ in both cohorts during the entire follow-up period (Figure 2 and Table 4).

\begin{tabular}{|c|c|c|c|c|c|}
\hline Number of patients ESC & First Line & Second Line & Third Line & Fourth line & Reason to change \\
\hline 1 & $\mathrm{AZT} / 3 \mathrm{TC} / \mathrm{NVP}$ & AZT/3TC/LPV & $\mathrm{ABC} / 3 \mathrm{TC} / \mathrm{EFV}$ & & $/ / N V P+V F$ \\
\hline 1 & $\mathrm{~d} 4 \mathrm{~T} / 3 \mathrm{TC} / \mathrm{LPV}$ & ABC/3TC/EFV & AZT/3TC/LPV & TDF/3TC/LPV & $/ / \mathrm{d} 4 \mathrm{~T}+\mathrm{VF}+$ anemia \\
\hline 1 & $\mathrm{~d} 4 \mathrm{~T} / 3 \mathrm{TC} / \mathrm{LPV}$ & $\mathrm{d} 4 \mathrm{~T} / 3 \mathrm{TC} / \mathrm{EFV}$ & & & VF \\
\hline 1 & $\mathrm{~d} 4 \mathrm{~T} / 3 \mathrm{TC} / \mathrm{LPV}$ & ABC/AZT/EFV & & & VF \\
\hline 1 & $\mathrm{~d} 4 \mathrm{~T} / 3 \mathrm{TC} / \mathrm{LPV}$ & ABC/3TC/EFV & & & VF \\
\hline 1 & $\mathrm{~d} 4 \mathrm{~T} / 3 \mathrm{TC} / \mathrm{LPV}$ & AZT/ABC/LPV/EFV & & & VF \\
\hline Number of patients LSC & First Line & Second Line & Third Line & Fourth line & \\
\hline 3 & $\mathrm{ABC} / 3 \mathrm{TC} / \mathrm{EFV}$ & AZT/3TC/LPV & & & VF \\
\hline 1 & $\mathrm{ABC} / 3 \mathrm{TC} / \mathrm{EFV}$ & $\mathrm{ddl} / \mathrm{AZT} / \mathrm{LPV}$ & & & VF \\
\hline 3 & $\mathrm{~d} 4 \mathrm{~T} / 3 \mathrm{TC} / \mathrm{EFV}$ & AZT/3TC/LPV & & & VF \\
\hline 1 & $\mathrm{~d} 4 \mathrm{~T} / 3 \mathrm{TC} / \mathrm{EFV}$ & ABC/AZT/LPV & & & VF \\
\hline 3 & $\mathrm{~d} 4 \mathrm{~T} / 3 \mathrm{TC} / \mathrm{EFV}$ & ddl/AZT/LPV & AZT/3TC/LPV & & $V F+/ / d d l$ \\
\hline 2 & $\mathrm{~d} 4 \mathrm{~T} / 3 \mathrm{TC} / \mathrm{EFV}$ & $\mathrm{ddl} / \mathrm{AZT} / \mathrm{LPV}$ & ABC/AZT/LPV & & $V F+/ / d d l$ \\
\hline 1 & $\mathrm{~d} 4 \mathrm{~T} / 3 \mathrm{TC} / \mathrm{LPV}$ & ddl/AZT/EFV & TDF/3TC/LPV & & $V F+/ / d d l$ \\
\hline
\end{tabular}

I/: No More Used Following National Recommendations; VF: Virological Failure; ESC: Early Starters Cohort; LSC: Late Starters Cohort; AZT: Zidovudine; 3TC: Lamivudine; NVP: Nevirapine; ABC: Abacavir; LPV: Lopiniavir/Ritonavir; TDF: Tenofovir; d4T: Stavudine; ddl: Didanosine; EFV: Efavirenz

Table 2: Successive treatments after virological failure in the ESC and the LSC.

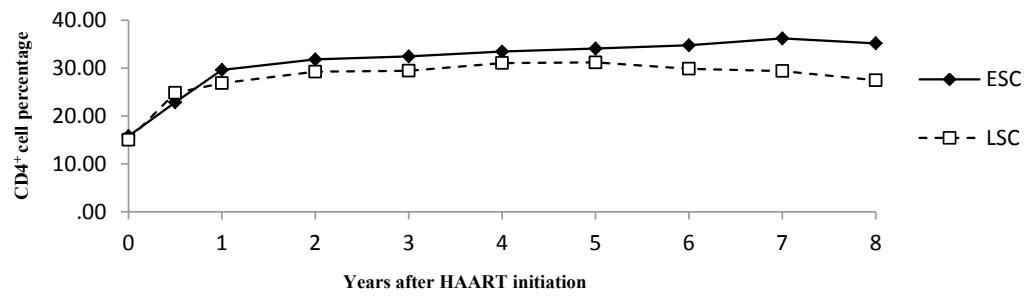

Figure 1: Mean CD4 in the ESC and the LSC.

\begin{tabular}{|c|c|c|c|c|c|c|c|c|c|c|}
\hline & 0 year & 0.5 year & 1 year & 2 years & 3 years & 4 years & 5 years & 6 years & 7 years & 8 years \\
\hline ESC mean CD4 $\%$ & $\begin{array}{c}15.8 \\
(55 / 55)\end{array}$ & $\begin{array}{c}22.9 \\
(52 / 55)\end{array}$ & $\begin{array}{c}29.6 \\
(47 / 55)\end{array}$ & $\begin{array}{c}31.8 \\
(47 / 55)\end{array}$ & $\begin{array}{c}32.4 \\
(47 / 55)\end{array}$ & $\begin{array}{c}33.5 \\
(49 / 55)\end{array}$ & $\begin{array}{c}34.1 \\
(47 / 55)\end{array}$ & $\begin{array}{c}34.8 \\
(52 / 55)\end{array}$ & $\begin{array}{c}36.2 \\
(33 / 55)\end{array}$ & $\begin{array}{c}35.2 \\
(17 / 55)\end{array}$ \\
\hline LSC mean CD4 $\%$ & $\begin{array}{c}15.0 \\
(96 / 96)\end{array}$ & $\begin{array}{c}24.8 \\
(75 / 96)\end{array}$ & $\begin{array}{c}\mathbf{2 6 . 9} \\
(72 / 96)\end{array}$ & $\begin{array}{c}29.3 \\
(77 / 96)\end{array}$ & $\begin{array}{c}29.5 \\
(79 / 96)\end{array}$ & $\begin{array}{c}31.1 \\
(66 / 96)\end{array}$ & $\begin{array}{c}31.2 \\
(51 / 96)\end{array}$ & $\begin{array}{c}29.9 \\
(51 / 96)\end{array}$ & $\begin{array}{c}29.4 \\
(32 / 96)\end{array}$ & $\begin{array}{c}27.5 \\
(17 / 96)\end{array}$ \\
\hline$p$ value & 0.59 & 0.26 & 0.088 & 0.13 & 0.064 & 0.13 & 0.067 & 0.042 & $<0.001$ & 0.013 \\
\hline
\end{tabular}

Numbers in brackets represent the number of data available for that year

Table 3: Mean CD4 $\%$ in the ESC and the LSC during the entire follow-up period. 
Citation: Beghin JC, Ruelle J, Goubau P, Krishna M, Hall L, et al. (2017) Virological and Immunological Long-Term Outcome of Human Immunodeficiency Virus-1 Infected Children Treated before One Year and after Two Years of Age in a Resource-Limited Setting of South Africa. J AIDS Clin Res 8: 690. doi: 10.4172/2155-6113.1000690

Page 4 of 7

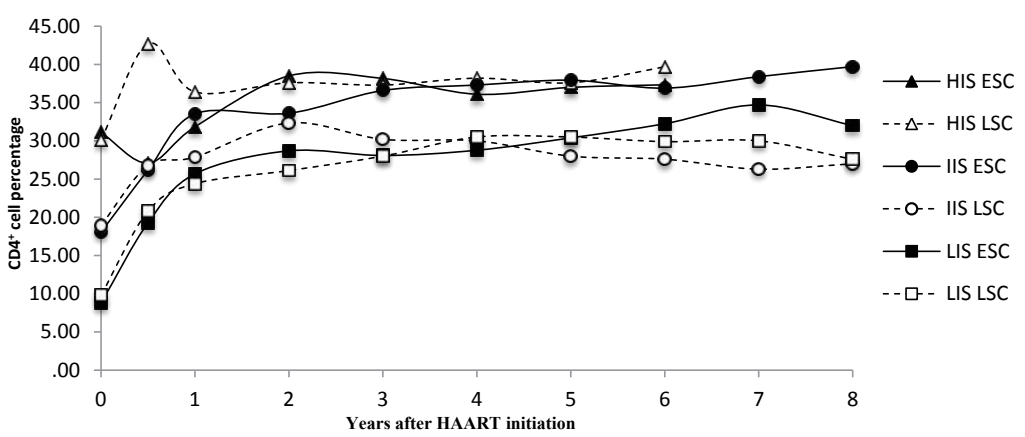

Figure 2: Mean CD4+\% of the LIS, IIS and HIS in the ESC and the LSC.

\begin{tabular}{|c|c|c|c|c|c|c|c|c|c|c|c|}
\hline & & 0 year & 0.5 year & 1 year & 2 years & 3 years & 4 years & 5 years & 6 years & 7 years & 8 years \\
\hline \multirow{3}{*}{$\begin{array}{l}\text { LIS } \\
\text { mean CD4+\% }\end{array}$} & ESC & $8.8(26 / 26)$ & $19.3(26 / 26)$ & $25.7(22 / 26)$ & $28.7(23 / 26)$ & $28.1(25 / 26)$ & $28.8(22 / 26)$ & $30.4(23 / 26)$ & $32.2(25 / 26)$ & $34.7(17 / 26)$ & $32.0(10 / 26)$ \\
\hline & LSC & $9.8(54 / 54)$ & $20.8(43 / 54)$ & $24.4(41 / 54)$ & $26.1(44 / 54)$ & $28.0(46 / 54)$ & $30.5(38 / 54)$ & $30.5(32 / 54)$ & $29.9(35 / 54)$ & $30.0(23 / 54)$ & $27.6(14 / 54)$ \\
\hline & $p$ value & 0.27 & 0.43 & 0.90 & 0.24 & 0.96 & 0.38 & 0.50 & 0.30 & 0.059 & 0.23 \\
\hline \multirow{3}{*}{$\begin{array}{l}\text { IIS } \\
\text { mean CD4 } \%\end{array}$} & ESC & $18.1(20 / 20)$ & $26.2(18 / 20)$ & $33.5(19 / 20)$ & $33.6(18 / 20)$ & $36.6(17 / 20)$ & $37.3(18 / 20)$ & $37.9(16 / 20)$ & $36.9(18 / 20)$ & $38.4(13 / 20)$ & $39.7(7 / 20)$ \\
\hline & LSC & $18.9(30 / 30)$ & $26.8(25 / 30)$ & $27.9(23 / 30)$ & $32.3(26 / 30)$ & $30.2(26 / 30)$ & $30.0(23 / 30)$ & $28.0(14 / 30)$ & $27.6(14 / 30)$ & $26.3(9 / 30)$ & $27.0(3 / 30)$ \\
\hline & $p$ value & 0.245 & 0.847 & 0.038 & 0.636 & 0.031 & 0.008 & 0.0007 & 0.014 & 0.002 & 0.001 \\
\hline \multirow{3}{*}{$\begin{array}{l}\text { HIS } \\
\text { mean CD4 } \% \text { }\end{array}$} & ESC & $31.1(9 / 9)$ & $27.1(8 / 9)$ & $31.8(6 / 9)$ & $38.5(6 / 9)$ & $38.2(6 / 9)$ & $36.1(8 / 9)$ & $37.0(8 / 9)$ & $37.3(9 / 9)$ & 1 & I \\
\hline & LSC & $30.1(11 / 11)$ & $42.7(7 / 11)$ & $36.4(8 / 11)$ & $37.6(7 / 11)$ & $37.3(7 / 11)$ & $38.2(6 / 11)$ & $37.6(5 / 11)$ & $39.7(3 / 11)$ & 1 & 1 \\
\hline & $p$ value & 0.63 & $<0.001$ & 0.33 & 0.82 & 0.79 & 0.60 & 0.89 & 0.38 & 1 & I \\
\hline
\end{tabular}

Numbers in brackets represent the number of data available for that year

Table 4: Variation of the CD4+\% in the LIS, the IIS and the HIS in function of the age at initiation.

\begin{tabular}{|c|c|c|c|c|c|c|c|c|c|c|c|}
\hline & & 0 year & 0.5 year & 1 year & 2 years & 3 years & 4 years & 5 years & 6 years & 7 years & 8 years \\
\hline \multirow{3}{*}{$\begin{array}{l}\text { Viral loads log } 10 \\
\text { (cp/mL) }\end{array}$} & ESC & 6.5 & 4.2 & 3.4 & 2.9 & 4.8 & 3.9 & 3.5 & 4.6 & 1.6 & 1.6 \\
\hline & LSC & 5.7 & 4.4 & 4.4 & 3.8 & 4.1 & 3.7 & 3.8 & 4.1 & 3.3 & 3.8 \\
\hline & $p$ value & $<0.001$ & 0.72 & 0.21 & 0.047 & 0.31 & 0.79 & 0.41 & 0.39 & 0.054 & 0.11 \\
\hline \multirow{3}{*}{$\begin{array}{l}\text { Virological failure } \\
(\%)\end{array}$} & ESC & 97.6 & 16.0 & 15.6 & 15.9 & 14.0 & 11.1 & 13.7 & 9.4 & 0.0 & 0.0 \\
\hline & LSC & 97.4 & 14.0 & 19.1 & 18.5 & 17.5 & 16.4 & 17.6 & 26.0 & 11.4 & 30.0 \\
\hline & $p$ value & 1 & 0.085 & 0.66 & 0.066 & 0.63 & 0.43 & 1 & 0.038 & 0.078 & 0.014 \\
\hline \multirow{2}{*}{$\begin{array}{l}\text { Number of data/ } \\
\text { year }\end{array}$} & ESC & 43 & 50 & 51 & 51 & 50 & 54 & 51 & 52 & 36 & 17 \\
\hline & LSC & 77 & 89 & 89 & 83 & 80 & 65 & 51 & 50 & 28 & 15 \\
\hline
\end{tabular}

Table 5: Viral loads and proportion of virological failure in the ESC and the LSC.

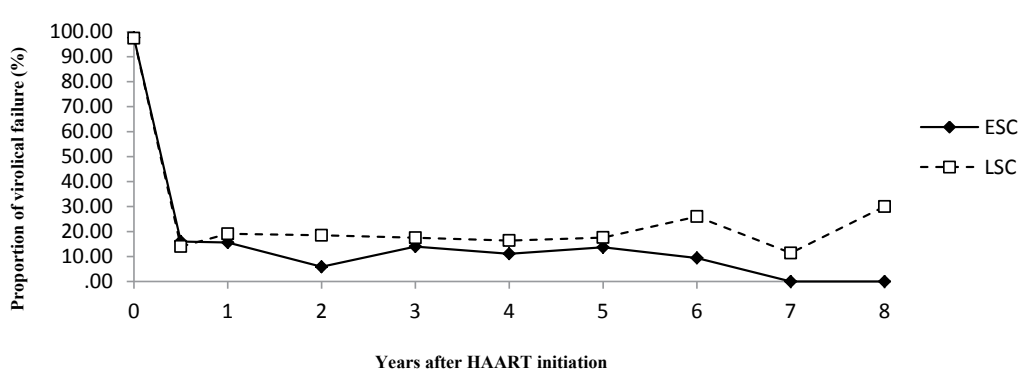

Figure 3: Proportion of virological failure in the ESC and the LSC.

\section{Virological outcome}

Pre-HAART VL was significantly higher in the ESC but the difference in VL waned 6 months after treatment initiation (Table 5).

In the ESC, $17 / 55$ (30.9\%) children experienced virological failure at least once after treatment initiation, 25/55 (45.5\%) never experienced virological failure and 13/55 (23.6\%) had detectable viral loads between 50 and $1000 \mathrm{cp} / \mathrm{ml}$ at least one time during the entire follow-up period.
In the LSC, 36/96 (37.5\%) children experienced virological failure at least once after treatment initiation, 19/96 (19.8\%) never experienced virological failure and 41/96 (42.7\%) had detectable viral loads between 50 and $1000 \mathrm{cp} / \mathrm{ml}$ at least one time during the entire follow-up period.

The proportion of children who experienced virological failure at least once after the first year of HAART was comparable in both cohorts when the entire follow-up period was considered $(p=0.48)$. However, when every year of follow-up was analyzed separately, proportion of 
Citation: Beghin JC, Ruelle J, Goubau P, Krishna M, Hall L, et al. (2017) Virological and Immunological Long-Term Outcome of Human Immunodeficiency Virus-1 Infected Children Treated before One Year and after Two Years of Age in a Resource-Limited Setting of South Africa. J AIDS Clin Res 8: 690. doi: 10.4172/2155-6113.1000690

Page 5 of 7

virological failure was higher in the LSC ( $p=0.038$ and 0.014$)$ at six and eight years of HAART, respectively (Figure 3 and Table 5).

The proportion of children with persistent undetectable VL after initial virological suppression was higher in the ESC than in the LSC $(p=0.008)$.

Finally, the proportion of children with detectable viral loads between 50 and $1000 \mathrm{cp} / \mathrm{ml}$ at least one time during the entire followup period was higher in the LSC $(p=0.0022)$.

\section{Discussion}

In 2012 , only $34 \%$ of the HIV-infected children were treated with HAART in the world [2]. The 2013 and 2015 WHO guidelines successively revised and simplified their recommendations to expand treatment in children and increase accessibility to HAART in RLS [2,3]. The present study evaluated the long-term impact and application of these recommendations in the field.

Both cohorts initiated treatment with three antiretroviral drugs as recommended by the WHO and the South African guidelines [2,20]. Children included in the ESC and the LSC initiated HAART with 2 NRTI and 1 PI or 2 NRTI and 1 NNRTI according to age, which means that the guidelines for the first line therapies are clear and correctly applied.

Second line therapies were more heterogeneous in both cohorts probably because different recommended options are available in the WHO [2] (e.g. LPV/r replaced by EFV, d4T+3TC replaced by $\mathrm{ABC} /$ $\mathrm{TDF}+3 \mathrm{TC}$ ) and the South African guidelines [20] (e.g. LPV/r replaced by $\mathrm{LPV} / \mathrm{r}+\mathrm{EFV}$ or a $3^{\text {rd }}$ line, $\mathrm{d} 4 \mathrm{~T}+3 \mathrm{TC}$ replaced by $\left.\mathrm{ABC}+\mathrm{AZT}\right)$. ddI is no more recommended in both guidelines but is still used in RLS. Finally, expert advice is recommended after first line failure with a $\mathrm{LPV} / \mathrm{r}$ based treatment. Experts are not always available and the choice of treatment depends more often on the habits of the local staff.

Immunological outcomes were favorable for both cohorts (ESC and LSC) and for the three subgroups (LIS, IIS, HIS), which underlines the importance of initiating HAART regardless of age. Children included in the ESC had at least comparable (or even better) immunological outcomes than children included in the LSC supporting the noninferiority of early treatment initiation, as recommended by the WHO and the South African guidelines.

Some favorable outcomes can be underscored. Before treatment, the ESC and the LSC both had a high proportion ( $47 \%$ vs. $56 \%)(p=0.56)$ of children with severe immunosuppression $(<15 \% \mathrm{CD} 4 \%)$. This is consistent with a review from Koller et al. who reported $70 \%$ of severe immunosuppression in children $<2$ years of age who started treatment in low and middle-income countries in 2010 [22]. Surprisingly, patients included in the present study had comparable mean $\mathrm{CD} 4^{+} \%$ independently of age at HAART initiation. It was not the case in European and West African studies [14,23] who showed more severe immunosuppression when treatment was started later in life $(-0.82 \%$ of mean $C D 4+\%$ per year of HAART initiation delay) [14]. This difference could be explained in our study by the exclusion of rapid progressors [24] who possibly died before 2 years (before HAART initiation) in the LSC.

Influence of age at baseline, independently of immunological status, was studied in European [23,25-29] and a few African cohorts (1-8.7 years follow-up) [14,30]. Results were unconclusive. Four studies [25-28] concluded the absence of influence of age at baseline and five studies [14,23,29-31] described poorer immunological outcomes for late starters. The follow-up study of CHER [16] compared early timelimited HAART with deferred HAART in 377 South African infants with a median follow-up of 4.8 years. Early treated children (median age 7.4 weeks, $\mathrm{CD} 4^{+} \%$ of $35 \%$ ) had better clinical and immunological outcomes than children treated later (median age 20 weeks, $\mathrm{CD} 4^{+} \%$ of $35 \%)$ even after planned treatment interruption at 40 or 70 weeks [16]. In our study, mean $\mathrm{CD} 4 \%$ was normal in both cohorts. However, there were statistically less children who achieved normal CD $4 \%$ in the LSC.

The European-American PENPACT-1 study [31], analyzed combined effects of $\mathrm{CD} 4^{+} \%$ and age at baseline. They found a significant interaction between $\mathrm{CD} 4^{+} \%$ and age on the probability of ever recovering a normal $\mathrm{CD} 4^{+} \%$ within 4 years. With increasing age, baseline $\mathrm{CD} 4^{+} \%$ had a stronger effect on the capacity to recover a normal $\mathrm{CD} 4^{+} \%$. Children included in our three subgroups achieved normal mean $\mathrm{CD} 4^{+} \%$ independently of their immunological status at baseline. There was no statistical difference in the number of children who achieved normal CD $4^{+} \%$ in the LIS and the IIS, probably due to the small effectives in these subgroups.

In terms of virological outcome, VL was higher in the ESC at treatment initiation. This could be explained by their younger age and was already described in untreated perinatally infected infants, who had the highest HIV-1 RNA levels at 2 months of age followed by a slow decline during the first two years of life. These high VL and slow decline reflect the lower efficiency of the immature immune system, which cannot contain the viral replication and has possibly a greater number of HIV-susceptible cells [32].

The proportion of children, who experienced virological failure at least once after initial suppression, was not significantly different in both cohorts; with $30.9 \%$ and $37.5 \%$ in the ESC and LSC respectively. A recent retrospective study implemented in another rural area of South Africa found similar rates (38\%) of virological failure (median duration since beginning HAART of 31 months) [13].

During the entire follow-up period, the proportion of children who sustained undetectable viral loads was significantly higher in the ESC and the proportion of children who experienced low-level viremia was higher in the LSC. Knowing that persistent low-level viremia is a risk factor of viral drug resistance [33,34], maintenance of an undetectable viral load decreases the risk to develop viral drug resistances in the ESC.

\section{Limitations}

This research has some limitations. It is a retrospective study that only includes a limited number of children who survived from 2005 until now and a number of children were lost to follow-up. Data collected at baseline could not be representative of all the infants from this region. Furthermore over the years some data were missing in the patients' files, which decrease the power of the study. However this is an operational study representing the real life on the field. Children included in the ESC and the LSC had, for most of them, different HAART regimens (PI vs NNRTI) at treatment initiation. A PI-based regimen initiation was described to be an advantage in terms of virological outcome in comparison with a Nevirapine-based regimen [35]. Our conclusions could be different if PI or NNRTI-based regimen were used in both cohorts.

\section{Conclusion}

HAART appeared highly effective in terms of immunological and virological long-term outcomes both in children treated before one year of age and after two years of age. The long-term results of this study 
Citation: Beghin JC, Ruelle J, Goubau P, Krishna M, Hall L, et al. (2017) Virological and Immunological Long-Term Outcome of Human Immunodeficiency Virus-1 Infected Children Treated before One Year and after Two Years of Age in a Resource-Limited Setting of South Africa. J AIDS Clin Res 8: 690. doi: 10.4172/2155-6113.1000690

Page 6 of 7

demonstrate that early HAART initiation was certainly not inferior to late treatment. Children from the ESC, treated with a PI-based regimen, more often achieved normal $\mathrm{CD} 4^{+} \%$ and sustained virological suppression than children from the LSC. These results encourage the current international recommendations to initiate HAART as soon as possible in RLS.

\section{Acknowledgement}

The authors thanks all the health personal of the Edendale hospital, the Doctor Antoine Bachy for his help in the implementation of this study and the Professor William D'Hoore who reviewed the statistical section of this article. We received a research fund from the FNRS (Fond National de Recherche Scientifique) to buy the material necessary for this study.

\section{Authors Contributions}

JCB and DVDL participated in the redaction of the questionnaires interpretation of the results and redaction of the article. JCB, MK and LH recruited the patients in the HIV family clinic. JCB, PG and JR participated to the redaction of the questionnaires, interpretation of the results and redaction of the article. All authors have read and approved the final manuscript.

\section{References}

1. World Health Organization, UNAIDS. AIDS Epidemic Update 2010. WHO library Cataloguing-in-Publication Data 2010.

2. World Health Organization, UNAIDS. Consolidated guidelines on the use of antiretroviral drugs for treating and preventing HIV infection: Recommendations for a public health approach. WHO Library Cataloguing-in-Publication Data 2013.

3. World Health Organization (2015) Guideline on when to start antiretroviral therapy and on pre-exposure prophylaxis for HIV. WHO Library Cataloguingin-Publication Data.

4. Violari A, Cotton MF, Gibb DM, Babiker AG, Steyn J, et al. (2008) Early antiretroviral therapy and mortality among HIV-infected infants. N Engl J Med 359: 2233-2244

5. Penazzato M, Prendergast AJ, Muhe LM, Tindyebwa D, Abrams E (2014) Optimisation of antiretroviral therapy in HIV-infected children under 3 years of age. Cochrane Database Syst Rev 22: 5.

6. Puthanakit T, Ananworanich J, Vonthanak S, Kosalaraksa P, Hansudewechakul R, et al. (2013) Cognitive function and neurodevelopmental outcomes in HIVinfected Children older than 1 year of age randomized to early versus deferred antiretroviral therapy: The PREDICT neurodevelopmental study. Pediatr Infect Dis J 32: 501-508.

7. Shiau S, Arpadi S, Strehlau R, Martens L, Patel F, et al. (2013) Initiation of antiretroviral therapy before 6 months of age is associated with faster growth recovery in South African children perinatally infected with human immunodeficiency virus. J Pediatr 162: 1138-1145.

8. Sutcliffe CG, van Dijk JH, Bolton C, Persaud D, Moss WJ (2008) Effectiveness of antiretroviral therapy among HIV-infected children in sub-Saharan Africa. Lancet Infect Dis 8: 477-489.

9. Reddi A, Leeper SC, Grobler AC, Geddes R, France KH, et al. (2007) Preliminary outcomes of a paediatric highly active antiretroviral therapy cohort from KwaZulu-Natal, South Africa. BMC Pediatr 7: 13.

10. Ciaranello AL, Chang Y, Margulis AV, Bernstein A, Bassett IV, et al. (2009) Effectiveness of pediatric antiretroviral therapy in resource-limited settings: A systematic review and meta-analysis. Clin Infect Dis 49: 1915-1927.

11. World Health Organization (2015) Antiretroviral therapy (ART) coverage among all age groups. Global Health Observatory $(\mathrm{GHO})$ data.

12. Rouet F, Fassinou $P$, Inwoley A, Anaky MF, Kouakoussui A, et al. (2006) ANRS 1244/1278 Programme Enfants Yopougon. Long-term survival and immuno-virological response of African HIV-1-infected children to highly active antiretroviral therapy regimens. AIDS 20: 2315-2319.

13. Barth RE, Tempelman HA, Smelt E, Wensing AM, Hoepelman Al, et al. (2011) Long-term outcome of children receiving antiretroviral treatment in rural South Africa: substantial virologic failure on first-line treatment. Pediatr Infect Dis J 30: $52-56$.

14. De Beaudrap P, Rouet F, Fassinou P, Kouakoussui A, Mercier S, et al. (2008) CD4 cell response before and after HAART initiation according to viral load and growth indicators in HIV-1-infected children in Abidjan, Côte d'Ivoire. J Acqui Immune Defic Syndr 49: 70-76.

15. Edmonds A, Yotebieng M, Lusiama J, Matumona Y, Kitetele F, et al. (2012) Quantification of CD4 responses to combined antiretroviral therapy over 5 years among HIV-infected children in Kinshasa, Democratic Republic of Congo. J Acquir Immune Defic Syndr 61: 90-98.

16. Cotton MF, Violari A, Otwombe K, Panchia R, Dobbels E, et al. (2013) CHER Study Team. Early time-limited antiretroviral therapy versus deferred therapy in South African infants infected with HIV: Results from the children with HIV early antiretroviral (CHER) randomised trial. Lancet 382: 1555-1563.

17. Penazzato M, Prendergast AJ, Muhe LM, Tindyebwa D, Abrams E (2014) Optimisation of antiretroviral therapy in HIV-infected children under 3 years of age. Cochrane Database Syst Rev 22: 5.

18. Shisana O, Simbayi LC, Rehle T, Onoya D, Jooste S, et al. (2012) South African National HIV Prevalence, Incidence and Behaviour Survey. Cape Town, HSRC Press.

19. Purchase SE, Van der Linden DJ, McKerrow NH (2012) Feasibility and effectiveness of early initiation of combination antiretroviral therapy in HIVinfected infants in a government clinic of Kwazulu-Natal, South Africa. J Trop Pediatr 58: 114-119.

20. Department of Health, Republic of South Africa (2014) National consolidated guidelines for the prevention of mother-to-child transmission of HIV (PMTCT) and the management of HIV in children, adolescents and adults.

21. Department for health, Republic of South Africa (2004) National antiretroviral treatment guidelines.

22. Koller M, Patel K, Chi BH, Wools-Kaloustian K, Dicko F, et al. (2015) Immunodeficiency in children starting antiretroviral therapy in low-, middle-, and high-income countries. J Acquir Immune Defic Syndr 68: 62-72.

23. Lewis J, Walker AS, Castro H, De Rossi A, Gibb DM, et al. (2012) Age and CD4 count at initiation of antiretroviral therapy in HIV-infected children: Effects on long-term T-cell reconstitution. J Infect Dis 205: 548-556.

24. Pizzo P, Wilfert C (1995) Report of a Consensus Workshop, Siena, Italy, June 4-6, 1993 Markers and Determinants of Disease Progression in Children with HIV Infection. JAIDS 8: 30-44.

25. Newell ML, Patel D, Goetghebuer T, Thorne C, European Collaborative Study (2006) CD4 cell response to antiretroviral therapy in children with vertically acquired HIV infection: Is it associated with age at initiation? J Infect Dis 193: 954-962.

26. Hainaut M, Ducarme M, Schandene L, Peltier CA, Marissens D, et al. (2003) Age-related immune reconstitution during highly active antiretroviral therapy in human immunodeficiency virus type 1 -infected children. Pediatr Infect Dis J 22: 62-69.

27. van Rossum AM, Scherpbier HJ, van Lochem EG, Pakker NG, Slieker WA et al. (2001) Therapeutic immune reconstitution in HIV-1-infected children is independent of their age and pretreatment immune status. AIDS 15: $2267-$ 2275.

28. Cohen S, Smit C, van Rossum AM, Fraaij PL, Wolfs TF, et al. (2013) Long-term response to combination antiretroviral therapy in HIV-infected children in the Netherlands registered from 1996 to 2012. AIDS 27: 2567-2575.

29. Kekitiinwa A, Lee KJ, Walker AS, Maganda A, Doerholt K, et al. (2008) Differences in factors associated with initial growth, CD4 and viral load responses to ART in HIV-infected children in Kampala, Uganda, and the United Kingdom/Ireland. J Acquir Immune Defic Syndr 49: 384-392.

30. Rouet F, Sakarovitch C, Msellati P, Elenga N, Montcho C, et al. (2003) Pediatric viral human immunodeficiency virus type 1 RNA levels, timing of infection, and disease progression in African HIV-1-infected children. Pediatrics 112: e289.

31. Yin DE, Warshaw MG, Miller WC, Castro H, Fiscus SA, et al. Using CD4 percentage and age to optimize pediatric antiretroviral therapy initiation. Pediatrics 134: e1104-e1116.

32. Shearer WT, Quinn TC, LaRussa P, Lew JF, Mofenson L, et al. (1997) Viral load and disease progression in infants infected with human immunodeficiency virus type 1. N Engl J Med 336: 1337-1342.

33. Taiwo B, Gallien S, Aga E, Ribaudo H, Haubrich R, et al. (2011) Antiretroviral drug resistance in HIV-1-infected patients experiencing persistent low-level viremia during first-line therapy. J Infect Dis 204: 515-520. 
Citation: Beghin JC, Ruelle J, Goubau P, Krishna M, Hall L, et al. (2017) Virological and Immunological Long-Term Outcome of Human Immunodeficiency Virus-1 Infected Children Treated before One Year and after Two Years of Age in a Resource-Limited Setting of South Africa. J AIDS Clin Res 8: 690. doi: 10.4172/2155-6113.1000690

Page 7 of 7

34. Laprise C, de Pokomandy A, Baril JG, Dufresne S, Trottier H (2013) Virologic failure following persistent low-level viremia in a cohort of HIVpositive patients: Results from 12 years of observation. Clin Infect Dis 57 1489-1496.
35. Barlow-Mosha L, Angelidou K, Lindsey J, Archary M, Cotton M, et al. (2016) Nevirapine versus lopinavir/ritonavir-based antiretroviral therapy in HIVinfected infants and young children: Long-term follow-up of the IMPAACT P1060 randomized trial. Clin Infect Dis 63: 1113-1121. 